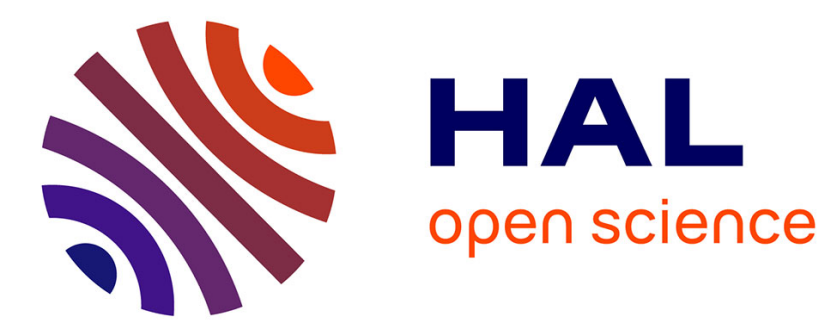

\title{
Automatic childbirth procedures implanted on the BirthSIM simulator
}

Osama Olaby, Richard Moreau, Xavier Brun, Tanneguy Redarce, Olivier

Dupuis

\section{- To cite this version:}

Osama Olaby, Richard Moreau, Xavier Brun, Tanneguy Redarce, Olivier Dupuis. Automatic childbirth procedures implanted on the BirthSIM simulator. 2006 IEEE/RSJ, Oct 2006, Pékin, China. pp.2370 - 2375, 10.1109/IROS.2006.282648 . hal-00369378

\section{HAL Id: hal-00369378 https://hal.science/hal-00369378}

Submitted on 9 Apr 2019

HAL is a multi-disciplinary open access archive for the deposit and dissemination of scientific research documents, whether they are published or not. The documents may come from teaching and research institutions in France or abroad, or from public or private research centers.
L'archive ouverte pluridisciplinaire HAL, est destinée au dépôt et à la diffusion de documents scientifiques de niveau recherche, publiés ou non, émanant des établissements d'enseignement et de recherche français ou étrangers, des laboratoires publics ou privés. 


\section{Automatic childbirth procedures implanted on the BirthSIM simulator}

\author{
O. Olaby, R. Moreau, X. Brun and T. Redarce \\ Laboratoire d'Automatique Industrielle \\ INSA de Lyon \\ Villeurbanne, FRANCE \\ osama.olaby@insa-lyon.fr
}

\author{
O. Dupuis \\ Service de Gynécologie \\ Hôpital de la Croix Rousse \\ Lyon, France \\ olivier.dupuis@chu-lyon.fr
}

\begin{abstract}
This paper presents some new automatic procedures for the BirthSIM childbirth simulator. This simulator is a complete training system used to simulate labor during childbirth and to mimic the last stage of a normal or instrumental delivery. This simulator also tests new techniques for obstetric practice. BirthSIM is able to simulate the uterine contractions and the mother's voluntary efforts, this enables the operator to synchronize these two types of efforts during a normal childbirth, or to synchronize these two efforts with the operator's tractive instrumental effort during childbirth using obstetric instruments. One originality of the BirthSIM simulator is to allow the medical team to acquire a better understanding of the application of these two synchronization concepts.

With the aim of implanting various childbirth procedures, four control algorithms and switching algorithms are used to control successively: force, position, force-velocity or forceposition. These control algorithms are important to produce the movement of the head, the mother's natural contractions and the mother's pushing action. Different childbirth cases are simulated using an electropneumatic system. The experimental results have been presented for two examples of instrumental extraction for childbirth using obstetric forceps (easy and difficult). The validity of the proposed control method for simulating childbirth modes has been evaluated by an expert obstetrician.
\end{abstract}

Index Terms - BirthSIM simulator, childbirth procedures, synchronization concepts in childbirth and control algorithms.

\section{INTRODUCTION}

Nowadays simulators in medicine have a real appeal in the medical environment. These tools enable doctors to visualize the position of the organs in the human body, to plan their movements and to carry out a more complete post operational control. In fact these simulations offer several advantages (safe training without any risks for the patients, saving of time and money, greater freedom for the operating theatre, etc). The training will be completed with experience learnt in the operating theatre. A birth simulator provides training and a research tool for comparing various techniques in the use of obstetrical instruments (forceps and vacuum extractors) or to validate new techniques.

In France, in 2003, 11.2\% of births required the use of obstetrical instruments $(6.3 \%$ by forceps and $4.9 \%$ by vacuum extractors). A study in the French Rhone-Alps area in 2002 shows that non-satisfactory training or a lack of experience in instrument handling carried out in emergency led to complications in $3.2 \%$ of births with an instrumental delivery [1] The dramatic consequences are that some obstetricians may finish their training without accumulating the necessary clinical experience to perform instrumental deliveries. The use of instrumented forceps [2] coupled with the BirthSIM simulator thus not only allows this training problem to be answered but also to ensure a quality control of instrumental deliveries.

A normal childbirth is divided into three stages: the dilation of the cervix uteri, the expulsion and the delivery. This study is especially interested in the expulsion part. This generally lasts between thirty minutes and two hours. It is the phase during which the fetus goes through the cervix uteri and crosses the bony pelvis and then the soft pelvis to the vulva.

The position of the fetal head is given by two parameters: station and location. The station of the fetal head is the distance of the head from the ischial spines as defined by the ACOG (American College of Obstetrics and Gynecology) 3]. This classification divides the pelvic canal into eleven stations from $-5 \mathrm{~cm}$ to $+5 \mathrm{~cm}$ every centimeter (see Fig. 1). The station $+5 \mathrm{~cm}$ corresponds to the instant where the fetal head is going to leave the vulva. The location concerns the rotation of the fetal head around the pelvic canal axis. Traditionally eight different locations (every $45^{\circ}$ ) are defined to describe the fetal head orientation [3]



Fig. 1 Descent of the head is described relative to the ischial spines

In order to validate the new childbirth procedures developed in this study, BirthSIM simulator has been used [4][5]. It consists of three parts: a mechanical part, an electropneumatic part and a visualization part [4] Only the mechanical and pneumatic parts are used in this study.

The BirthSIM simulator mechanical part is made of anthropomorphic models of the maternal pelvis and the fetal head. This head has the main anatomical landmarks (fontanels, 
sutures, ears) and these enable a realistic examination of the fetal head [4]. The maternal pelvic model also has anatomical landmarks: ischial spines, pubis, coccyx and sacrum. An interface system, consisting of an elastomer, mimics the pelvic muscles and fills the gap between the fetal head and the pelvic model. It is soft enough for the medical team to examine manually the underlying ischial spines. With this simulator the medical team can feel the usual landmarks and can acquire haptic feeling as in a real delivery. They can make their diagnosis and the transvaginal assessment [1]. This diagnosis is to determine the position of the fetal head inside the pelvis to establish which procedures will used for the delivery (vaginal delivery, Cesarean or instrumental delivery).

The head is linked to a ball and socket. This joint can be blocked to ensure the repeatability of experiments. This joint is connected to a linear pneumatic actuator driven by two fiveport proportional valves. In fact the electropneumatic part uses two actuators which enable the user to choose a station and a location. A pneumatic actuator (respectively a DC motor) ensures the placement of the head at the desired station (respectively the location). So to complete the expulsion part of the labor, the medical team must help the mother to synchronize her thrust with the uterine contractions at a normal birth; or must synchronize their tractive efforts with the maternal efforts produced when an instrumental birth takes place. These two concepts are to overcome the resistance threshold necessary to expel her baby out of her uterus. In addition to its role of positioning the head, the pneumatic actuator also makes it possible to reproduce the various efforts which operate during a childbirth [6]

- Resistive efforts of the pelvic muscles which tend to prevent the baby from advancing along the pelvic canal ;

- involuntary uterine contractions which are produced regularly by the mother;

- voluntary thrusts of the mother to expel the baby out of the pelvis.

This article is organized as follows: In section II, involuntary efforts, voluntary efforts and two synchronization concepts are described. In section III, simulation of uterine contractions and the mother's efforts via BirthSIM have been provided. Section IV presents four control and switching algorithms used for realizing various implanted birth procedures. Section V discusses the experimental results obtained for the static training mode and the two dynamics training modes for childbirth procedures.

\section{MATERNAL EFFORTS AND SYNCHRONIZATION CONCEPTS}

During the second stage of a labor, the fetus is submitted to two types of phenomena. The first is uterine contractions (UC); this is an involuntary activity of the mother generated by the uterine muscles. The UC are a source of involuntary efforts (IVE). The second type of phenomena is maternal expulsive efforts, this is a voluntary activity of the mother solicited by a midwife or an obstetrician. These are the source of voluntary efforts (VE).

\section{A. Involuntary Efforts i.e. UC}

The uterine contractions are due to the activity of muscles, essentially in the wall of the uterus. This contractile activity of the uterus makes it possible to push the fetus out [7] It is painful activity and can be identified by the mother who can feel it, and by the obstetrician who can watch these UC on a tocography and can palpate these contractions on the mother's lower belly or feel the head advancing with each UC.

Recording by internal tocography makes it possible to represent the intra-abdominal pressure variations as a function of time as shown in Fig. 2. This curve, traced for ten minutes, can be described using several parameters:

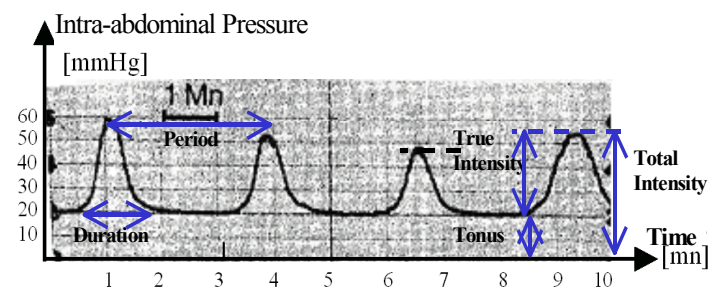

Fig. 2 Tracing the uterine contractions and their parameters [6].

- Tonus is the value of a minimal intra-uterine pressure.

- Total intensity is defined as the maximum intra-uterine pressure reached.

- True intensity represents the effective UC, it is defined as: True intensity $=$ Total Intensity - Tonus

- Frequency is the number of UC per ten minutes.

- Duration of the contractions is expressed in seconds.

- Uterine activity (Montevideo units) is given as:

Uterine activity $=$ True Intensity $\times$ Frequency of UC

The characteristics of the uterine contractions vary from one mother to another. Table 1 shows normal values of UC parameters in the second stage of labor.

TABLE I

Normal values of the various UC parameters during the second stage of labor 6]

\begin{tabular}{|l|c|}
\hline \multicolumn{1}{|c|}{ Parameter } & $\begin{array}{c}\text { Quantitative } \\
\text { measurements }\end{array}$ \\
\hline Tonus (mm Hg) & $9 \pm * 4$ \\
\hline True intensity (mm Hg) & $39 \pm 17$ \\
\hline Total intensity (mm Hg) & $48 \pm 17$ \\
\hline $\begin{array}{l}\text { Maximum values of the true } \\
\text { intensity (mm Hg) }\end{array}$ & 73 \\
\hline Frequency (per10 min) & $4.4 \pm 1.8$ \\
\hline Duration (s) & $74 \pm 16$ \\
\hline Uterine activity (mm Hg) & from 34 to 222 \\
\hline
\end{tabular}

$\left.{ }^{*}\right) \pm$ Represents the maximum and the minimum.

\section{B. Voluntary Expulsive Efforts}

Maternal expulsive efforts are added to the phenomenon of the UC. These efforts from the mother press the uterus by rising the intra-abdominal pressure between 30 and $50 \mathrm{mmHg}$ as shown in Fig. 2. They can be provided by the mother when she pushes the baby at the moment when the obstetrician requires it, or by a midwife who applies an external effort using her hands on the mother's belly (not simulated in this study). This case occurs when the mother is tired and is unable to provide a sufficient thrust. 


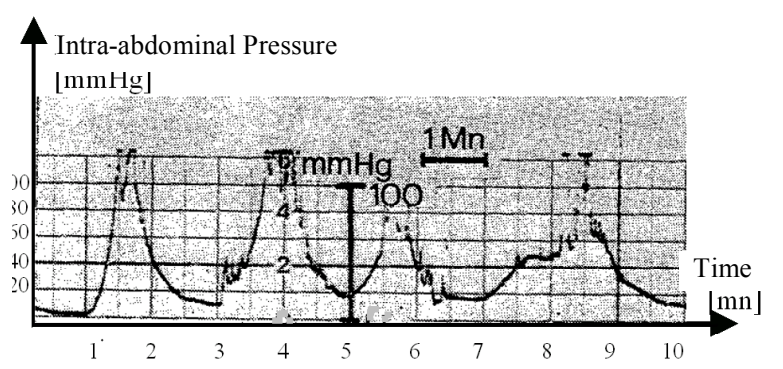

Fig. 3 Maternal expulsive efforts added to the UC [6]

During a normal labor, there are generally 3 to 4 voluntary expulsive efforts per minute, each effort lasts between ten and thirty seconds. These efforts vary with each woman and can reach pressures of $120 \mathrm{mmHg}$ as shown in

Fig. 3

\section{Synchronization Concept in a normal childbirth}

In this case the total explosive efforts which enable the progression of the fetus are the IVE and the VE. The concept of simple synchronization consists of synchronizing these two forces. To overcome the mechanical resistance, it is necessary to ensure that the uterine contractions and the voluntary expulsive efforts are quite synchronous (see Fig. 4(a)). If the total efforts are higher than the resistance threshold, the progression of the baby inside the vagina occurs. This concept of resistance threshold is very difficult to quantify. It depends on the mechanical properties of the uterus and the vagina, these are defined by the resistance force exerted by the walls of the organs on the fetus. In this study the threshold is supposed constant at any moment but adjustable before each test.

Fig. 4(a) shows a very good synchronization, whereas Fig.4(b) presents a minimum synchronization which passes the resistance threshold. In this case, synchronization is applied for a short time which will only cause a poor progression of the fetus.

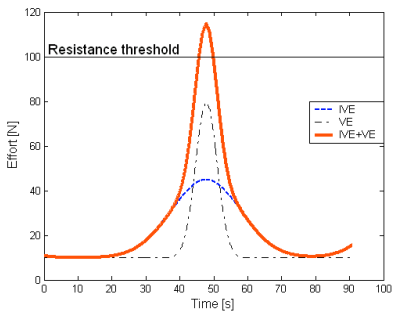

a. Perfect synchronization



b. Good synchronization
Fig. 4 Application of a simple synchronization concept: Fetus progression is possible

\section{Synchronization concept in Instrumental Childbirth}

During childbirth by instrument obstetrics (forceps or vacuum extractor), the forces which enable the progression of the fetal head are of three types. A tractive effort carried out by an obstetrician during the extraction is added to the two IVE and VE efforts which appear during normal labor.

Two principles are explained by [2] to show why the tractive effort (TE) developed during an instrumental extraction must be as weak as possible. Thus the obstetrician must synchronize his TE with the VE and with the IVE. This is called "concept of double synchronization". In fact, to overcome the mechanical resistance in an instrumental childbirth, it is necessary to apply this synchronization concept which is shown in Fig. 5. The mechanical resistance in this case is related to a macrosomia or a too narrow pelvis. At the identical resistance threshold, the operator must take care to obtain the best synchronization possible so as to use the weakest instrumental force possible [9]
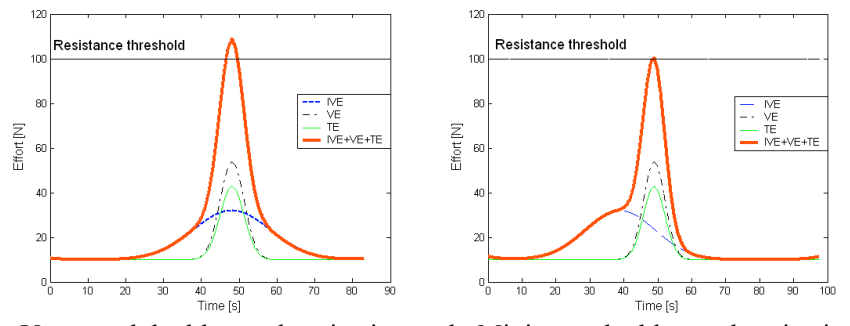

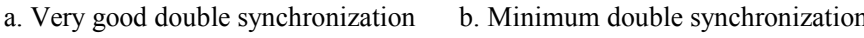
Fig. 5 Application of double synchronization concept: Fetus progression is possible

A synchronization defect has major consequences. This can result in unnecessarily high forces being exerted during an instrumental extraction. This unnecessarily high force should be avoided [9]. Bad synchronization, shown in Fig. 6, can be related to the parturient. This is the case when the mother has insufficient analgesia or is nervous. Bad synchronization can also be related to an obstetrician who is not able to synchronize his tractive efforts with those UC and VE of the mother, or forgets to request the mother's pushing efforts.

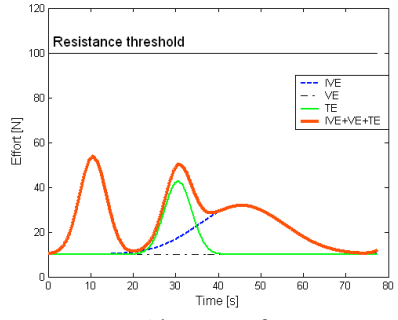

a. Absence of any synchronization concept

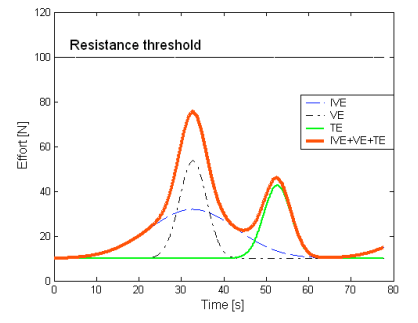

b. Application of a simple synchronization but not a double one
Fig. 6 Fetus progression is not possible

\section{SIMULATION OF UTERINE CONTRACTIONS AND MOTHER'S EFFORTS}

Today BirthSIM is able to simulate the IVE and the VE. Fig.7 shows a graph simulating the $\mathrm{CU}$, each contraction has been given by a Gaussian function as follows:

$$
G(t)=\exp \left(-\frac{t^{2}}{\mathrm{~d}_{\mathrm{UC}}}\right)
$$

$G(t)$ : Gaussian function as function of time $t$

$\mathrm{d}_{\mathrm{UC}}$ : Duration of one contraction

The UC simulated are described using four parameters with the aim of representing the real uterine contractions shown in Fig. 2. Fig. 7 defines these four parameters with an important new one: $d_{2 s t a g e}$ which represents a duration of a second stage of labor. $d_{2 s t a g e}$ is an adjustable time lasting between ten minutes and two hours, It is a real time of labor allowing the fetal head to leave the pelvis entirely [7]. 


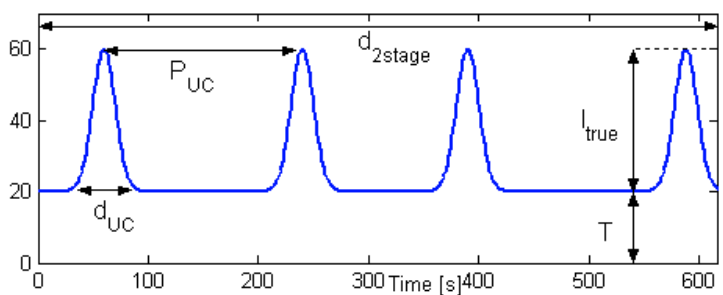

Fig. 7 Uterine contractions (i.e. IVE) realized by BirthSIM

Fig. 7 presents a series of the IVE synchronized with the VE starting from the second VE. A threshold of mechanical resistance of $100 \mathrm{~N}$ is supposed, this shows that the simple synchronization concept is carried out starting from the third IVE. This synchronization is minimum and then it is good for the fourth IVE. The instructor, who is an expert obstetrician, can control the VE by three adjustable parameters, he can choose in real time the beginning, the end and the intensity of each VE as shown in Fig. 8.

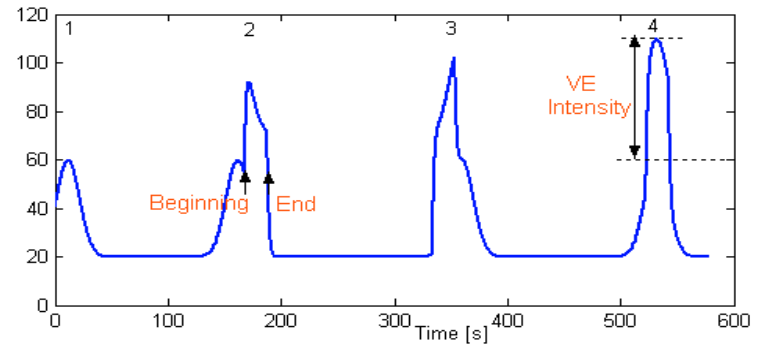

Fig. 8 Total efforts (IVE and VE) realized via BirthSIM in real time

BirthSIM is able to visualize the position of the fetal head in the vaginal canal, the uterine contractions and the mother's voluntary efforts. This enables the operator to be able to synchronize these two types of efforts during a normal childbirth, or to synchronize these two efforts with the tractive instrumental effort during a childbirth by obstetric instruments.

By considering the graph shown in Fig. 7 and Fig. 8 as desired input trajectories for the electropneumatic system chosen for the BirthSIM simulator [4]. The medical conditions are translated into an automation problem. This makes it possible to automate the BirthSIM childbirth simulator. In fact, the BirthSIM is able today to realize ten operating modes equivalent to various childbirth procedures. One mode for static training and the rest for dynamic training as will be shown in section $\mathrm{V}$.

\section{CONTROL ALGORITHMS}

Fig 10 shows an electropneumatic system chosen to reproduce ten different childbirth procedures. The system under consideration is a linear inline double acting electropneumatic servo-drive using a single rod controlled by two five-port proportional valves. A global characterization [10][11] of this electropneumatic proportional valve has been carried out to obtain an analytical model. In this case the nonlinear model has been linearized around an equilibrium set. This is useful for scheduling the controller gains of the control algorithms. The two proportional valves are controlled with opposite sign inputs of $\left(\mathrm{U}_{t}\right.$ and $\left.-\mathrm{U}_{t}\right)$ in the system under consideration for all the control algorithms.
The newborn's head is connected to the pneumatic actuator which, in addition to its role of positioning the head, reproduces the various efforts during labor.

This system has three sensors as shown in Fig. 9. The head station $\mathrm{x}$ is given by an analog potentiometer and the two pressures $\mathrm{P}_{1}$ and $\mathrm{P}_{2}$ (in the two cylinder chambers) are given by two analog pressure sensors. The sensor data was run through a signal conditioning unit before being read by a dSpace acquisition board. The software Control Desk provided with a dSpace DS1104 controller board, displays this digital data.

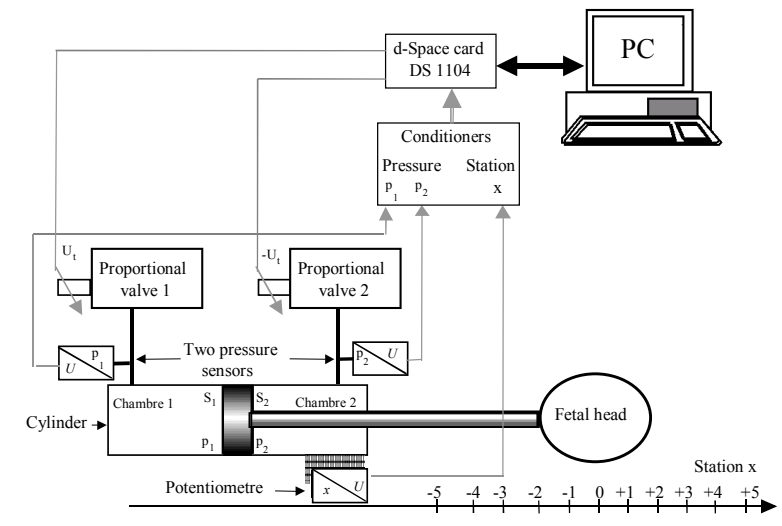

Fig. 9 Electropneumatic system of BirthSIM

With the objective of implanting ten childbirth procedures, four control algorithms and switching algorithms are used to control successively: force, position, force-velocity or force-position. Reference [11] proposed a hybrid control methodology to switch between special objectives without damage to the process.

The first control algorithm is a force tracking control (see Fig.10) which is important to produce the mother's natural contractions and the mother's pushing action. The aim of this control algorithm is to be accurate in terms of force tracking for a desired input trajectory represented by the IVE shown in Fig. 7 and the VE shown in Fig. 8. The force of pressure $F_{P}$ is estimated from two pressure sensors as shown in Fig.10.

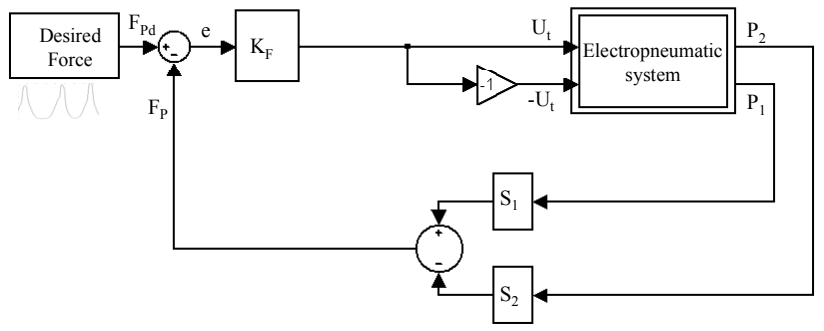

Fig.10 Force tracking

The second control algorithm is a position feedback control (see Fig. 11) which is necessary to position the head on an initial station by controlling the electropneumatic system by fixing the controller gain $\mathrm{K}_{\mathrm{x}}$. Then this algorithm is used by varying the controller gain $\mathrm{K}_{\mathrm{x}}$ at the time, to produce one of the difficult instrumental childbirth procedures. In this case, a desired input trajectory has been carefully chosen in order to simulate a difficult childbirth using forceps as will be explained in the next section. In order to obtain a good step 
position response in each station, velocity and acceleration feedback is achieved. A robust numerical differentiator via the sliding mode technique proposed in [13] is used to recover the velocity and the acceleration signals for all control algorithms used in this study.

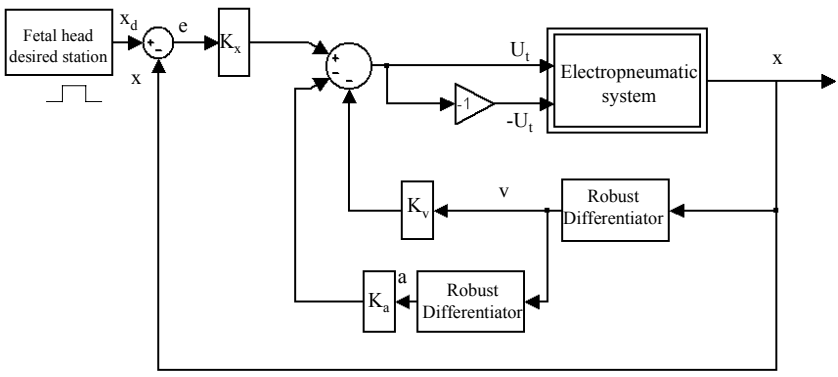

Fig. 11 Step position response

The third control algorithm depends on switching between force tracking control (first algorithm shown in Fig.10) and position control (second algorithm shown in Fig. 11). This algorithm can be useful for examining the management of a midwife to achieve delivery of a normal healthy child with minimal physical problems for the mother. In vivo, when the mother, asked by a midwife, pushes very hard a long and fast displacement of the head can be occur. In this dangerous case, the midwife must take care to retain the head to avoid tearing the perineum.

The fourth control algorithm concerns switching between force tracking control (first algorithm shown in Fig.10) and velocity regulation control (see Fig. 12). This control algorithm can simulate the second stage of normal labor. The force tracking enables the fetal head to be maintained in a position between two contractions in order to reproduce a resistive effort of the pelvic muscles which tend to prevent the baby advancing in the pelvic canal. Whereas the velocity regulation allows the baby's progression when the IVE reaches its peak.

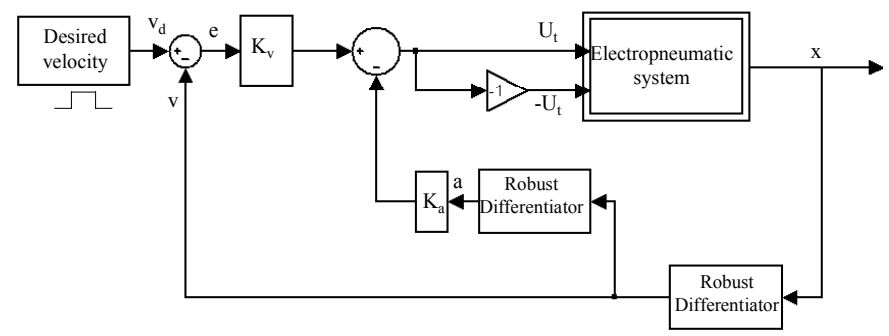

Fig. 12 Velocity regulation

In the two last control algorithms, the switching occurrence does not depend of an external signal, but is programmed online for desired tracking objectives.

\section{EXPERIMENTAL RESULTS}

This paragraph presents a static training mode, then two dynamic training modes of nine childbirth procedures realizable today as operating modes for the BirthSIM simulator.

\section{A. Automatic installation of the fetal head in one station}

Using the control algorithm shown in Fig. 11, BirthSIM is able automatically, on a request of the instructor, to position the fetal head in one of the eleven stations shown in Fig. 1. This mode can be an initialization mode for the other modes. Another important use of this mode can be also to train the operator (midwife or junior obstetrician) to recognize a head station from sciatic spines by simple vaginal examination [8].

The two dynamic training modes for simulating an extraction using obstetric instruments at the second stage of labor are carried out with the aim of:

- training junior obstetricians to use forceps for various positions of the head in the vaginal canal [6] and for various levels of a resistance [2] which require an easy, difficult or impossible extraction using obstetric instruments.

- training to apply the concepts of simple and double synchronization

- $\quad$ examining the quality of instrumental extraction achieved by the juniors.

B. Realization of an easy extraction by forceps when the mother cannot push (training for the simple synchronization)

In this mode an operator must be able to apply the concept of simple synchronize of the uterine contractions (IVE) and the instrumental tractive effort (TE) when the voluntary effort (VE) is not sufficient. This mode supposes that the voluntary expulsive efforts generated by the mother are of low intensities e.g. the mother is tired and she cannot push well.

To carry out this mode, the algorithm must firstly be initialized, and then the force tracking control algorithm shown in Fig.10 can be applied. For the initialisation the instructor must choose the initial position (among the eleven possible stations) via the first mode and define the amplitude of the movement with which a labor can be simulated: between +15 and +20 .

Fig. 13 shows a response of the pneumatic system to a desired input force trajectory applied to the fetal head. The form of this trajectory simulates the UC (see Fig. 2). In Fig. 13 the effort's trajectory is applied to the head placed at station 0 . As an operator can carry out well the simple synchronization concept for each arrival of the UC, the head advances for each effort. The amplitude of displacement depends on the synchronization quality achieved and on the tractive force applied by the operator. Fig. 13 shows a progression equal to two stations for each synchronization of the IVE with the TE. Fig. 13.

The system's response is accurate in terms of force tracking except in the time intervals when the head advances, under an application of the TE. For example at $t=109 \mathrm{~s}$ (see Fig. 11) an operator pulls the head using forceps which causes immediately a reduction in the pressure force $F_{P}$ (pressure $\mathrm{P}_{1}$ increases whereas $P_{2}$ decreases as shown in Fig. 9). But the electropneumatic system is in tracking force trajectory control, the influence of this disturbance is attenuated by the feedback by increasing the input control $\mathrm{U}_{1}$. The corrector gain $\mathrm{K}_{\mathrm{F}}$ can 
be increased if it is wished to decrease the amplitude of the variation $F_{P}$ which is $6 \mathrm{~N}$ in Fig. 14. This gain has an immediate influence on the system stiffness. In fact, the principle interest of choosing a pneumatic system for the BirthSIM is the ability to regulate this stiffness easily for simulating in vivo cases. Thus at $\mathrm{t}=109 \mathrm{~s}$ an instrumental tractive effort makes the head advance from station +2 to $a+4$. This scenario can be repeated near each UC peak if the operator pulls the fetal head.


Fig. 13 Realization of an easy forceps delivery when the mother cannot push (training the concept of simple synchronization)
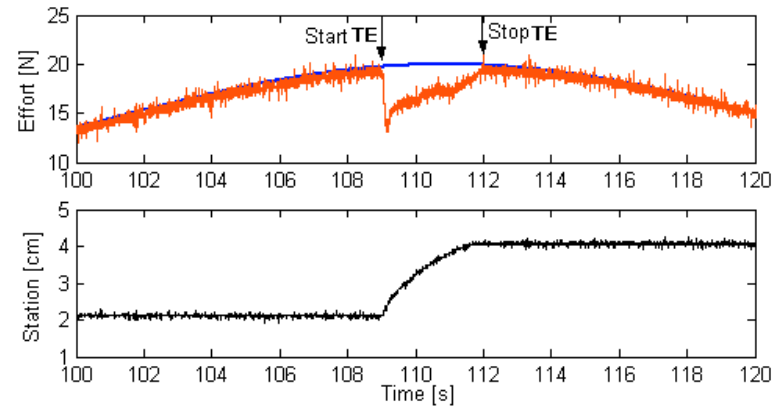

Fig. 14 Zoom of a second UC shown in Fig. 13, an easy forceps delivery when the woman cannot push

C. Realization of difficult forceps delivery when the woman can push (training for the concept of double synchronization)

This mode makes it possible to simulate a delivery using obstetric instruments. This mode is more difficult than the mode presented. Because, in this case, the effort applied to the head is stronger. In this mode the instructor can press on one button in an graphic interface at the moment when the operator asks the mother to push. This can address, to the BirthSIM, a signal to make it possible to reduce the effort applied to the head and so reduce the TE which the operator must provide. This reduction must last between 10 and 30 seconds as it does in reality (see Fig. 3). It can have three different intensities: weak, moderate or strong, which corresponds respectively to $10 \%, 30 \%$ and $60 \%$ of the tractive effort provided by the operator. If the principle of double synchronization is applied perfectly, the fetus can be moved forward with a force which is the sum of the IVE, the VE and the TE.

To realized this mode, the step position control algorithm shown in Fig. 11 is applied. The desired input signal in this control algorithm creates the oscillation of the new-born in the vaginal channel. This can happen in practice but in our case one step was defined to ensure a slight progression of the newborn. In fact, In this mode, if the operator manages to carry out the concept of double synchronization, the head advances at least one step (which equals one station in this study) so it reaches a new position. Thus, the new desired position has a new value equal to the new station occupied by the head. Moreover, in this mode, the controller gain $\mathrm{K}_{\mathrm{X}}$ is not constant (see Fig. 15). So this gain can have values between 5 and 70 . The low values of $K_{X}$ reduce the effort applied to the fetal head. In fact, the tractive effort provided by the operator can have three different intensities, strong, moderate or weak. This is simulated by decreasing the gain $\mathrm{K}_{\mathrm{X}}$ more and more and so decreasing the system stiffness. The $K_{X}$ curve shown in Fig. 15 can be considered as the opposite of the Fig. 3 curve.

The result presented in Fig. 1 shows that the application of double synchronization is achieved well three times successively by the operator. In fact, the operator asked the mother to push according to the curve of Fig. 15 during a period of low values of $\mathrm{K}_{\mathrm{x}}$ and at same moment he applied his tractive effort. So the head advanced 4 stations from +5 to +9 . This scenario can be repeated by the operator for the next reduction in $K_{x}$ values shown in Fig. 15. Fig. 1 shows a head advance of five stations during the second application of double synchronization. For the third application of this concept the head arrives at station +20 .

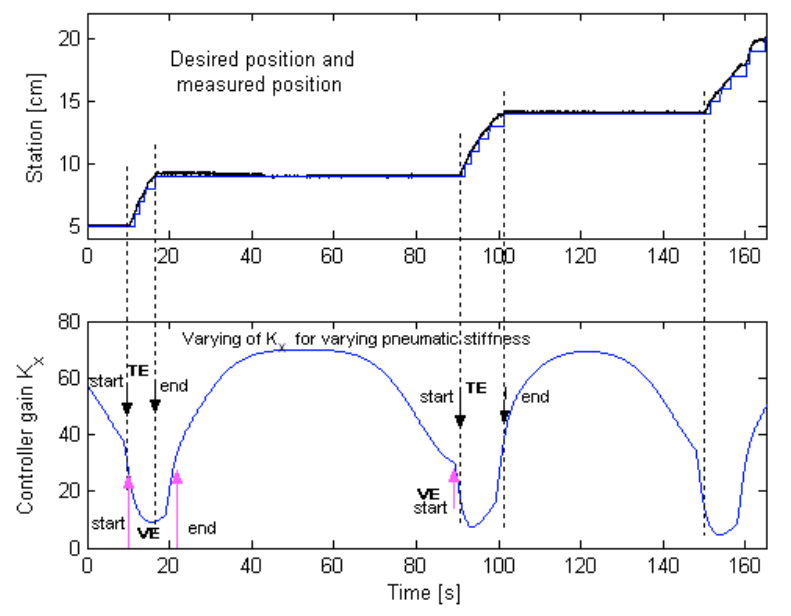

Fig. 15 Realization of a difficult forceps delivery when the mother can push (training for double synchronization)

\section{CONCLUSION}

This paper presents the development of a childbirth simulator whose characteristics correspond to the need of obstetricians. The childbirth procedures implanted, including the three presented in this article, make BirthSIM an active and dynamic simulator. The instrumentation used can transmit in real time the following information to the operator:

- station, progression and velocity of the head and possibly its acceleration;

- form of pressure effort trajectories developed by the pneumatic actuator; 
- tractive effort developed by the operator;

The operators can use this information to learn how to achieve the synchronization necessary between different efforts produced during labor with maximum safety.

Currently several features of the BirthSIM simulator are under development and validation. The first point relates to the pneumatic actuator which reproduces the efforts on the fetal head. Two directions of research are currently in hand: synthesis of nonlinear control laws of the electropneumatic system and the development of an interface allowing the simulation of the pelvic muscles. The second point is based on the training of a reference obstetric movement with a $3 \mathrm{D}$ visualization interface and on the comparison of the repeatability of the application of synchronization concepts between novice obstetricians and expert obstetricians using obstetrical forceps or a vacuum extractor.

\section{REFERENCES}

[1] Dupuis O., Silveira S., Redarce T., Dittmar A., and Rudigoz R.-C. Operative vaginal delivery rate and neonatal associated complications in 2002 in the AURORE hospital network. Gyn' ecologie Obst' etrique et Fertilit' e, 31(11):920-926, 2003.

[2] Dupuis O., et al "A new obstetric forceps for the training of juniors doctors. a comparison of the spatial dispersion of forceps blade trajectories between junior and senior obstetricians". American Journal of Obstetrics and Gynecology. AJOG, in press.

[3] Cunningham G., Gilstrap L., Leveno K., Bloom S., Hauth J., and Wenstrom K. Williams "Obstetrics". The McGraw-Hill Companies, $22^{\text {nd }}$ edition, 2005,1448 p. ISBN 0071413154.

[4] Silveira R., Dupuis O., Pham M.T., Rerdarce T., Betemps M. "A new mechanical birth simulator". IEEE/RSJ International Conference on Intelligent Robots and Systems - IROS'04, 28/09-2/11 2004, Sendai, Japan, 2004, pp 3948-3953.

[5] Dupuis O., Dittmar A., Delhomme, G., Redarce T., Betemps, M., Silveira S., Simulateur fonctionnel et anatomique d'accouchement. French patent number: 0309569, August 01, 2003.

[6] Thoulon J.-M. "Le monitorage électronique fœtal $\mathrm{La}$ cardiotocographie". $2^{\text {ème }}$ ed. Paris : MASSON, 1991.ISBN 2-22582251-4

[7] Papiernik E., Cabrol D., Pones J-C. "Obstétrique". Paris, France :Flammarion médecine-sciences, 1995, 1584 p. ISBN: 2-25715045-7.

[8] Dupuis O., et al, "Birth simulator: Reliability of transvaginal assessment of fetal head station as defined by the American College Obstetricians and Gynecologists classification". American Journal of Obstetrics and Gynecology (AJOG), 192:868-874, 2005.

[9] Moreau R., Dupuis O., Pham M.T., and Rerdarce T. "Paths analysis for a safe forceps blades placement on the BirthSIM simulator" IEEE International Conference on Robotics and Automation. ICRA2006., in press.

[10] Olaby O., Brun X., Sesma S., Redarce T., Bideaux E., Characterization and Modeling of a proportional valve for control synthesis, $6^{\text {th }}$ JFPS Internat. Symp. on Fluid Power, Dec 2005. Tsukuba, Japan.

[11] Brun X, Thomasset D, Scavarda S, "Hybrid control for switching between position and force tracking". The Fourth International Symposium on Fluid Power Transmission and Control, pg. 44-49, Wuhan-Chine. 08/04/2003-10/04/2003.

[12] Fernandez-Jimenez, A., Perez Garcia, J., Compressible bench flow adaptations to the experimental characterization of pneumatic components. Application to the determination of flow-rate characteristics of a MPYE-5-3/8-010-B proportional valve, $3^{\text {rd }}$ International Ph.D. Symposium on Fluid Power, Terrassa, Spain, $30^{\text {th }}$ June- $2^{\text {nd }}$ July, 2004, p 139-148.
[13] Smaoui M., Brun X.,Thomasset D., A Robust differentiator-controller design for electropneumatic system, $44^{\text {th }}$ IEEE Conferance on Decision and Control, and the European Control Conferance 2005, 12-15 Dec 2005, Teville, Spain, p 4385-4390

[14] Olaby O., Brun X., Redarce T.," Automation of a mechanical childbirth simulator using electropneumatic components". Fluid Power Net International $-4^{\text {th }}$ FPNI-PhD Symposium, 13/06-17/06 2006, Sarasota/Florida, USA, 2006, in press.

[15] Fleming A.R., Brandeberry K.R., and Pearse W.H. Introduction of a metric forceps. American Journal of Obstetrics and Gynecology $(A J O G), 78: 125-133,1959$.

[16] Moreau R., Dupuis O., Pham M.T., and Rerdarce T. "Paths analysis for a safe forceps blades placement on the BirthSIM simulator" IEEE International Conference on Robotics and Automation. ICRA2006., in press. 